\title{
COMPOSIÇÃo IÔNICA MAJORITÁRIA DE ÁGUAS DE CHUVA NO CENTRO DA CIDADE DE SÃo PAULO
}

Tatiana F. M. Leal, Anna P. G. Fontenele e Jairo J. Pedrotti*

Departamento de Química, Universidade Presbiteriana Mackenzie, Rua Itambé, 45, 01239-902 São Paulo - SP

Adalgiza Fornaro

Departamento de Ciências Atmosféricas, Instituto de Astronomia, Geofísica e Ciências Atmosféricas, USP,

Rua do Matão, 1226, 05508-900 São Paulo - SP

Recebido em 2/6/03; aceito em 28/4/04; publicado na web em 27/07/04

\begin{abstract}
COMPOSITION OF RAINWATER IN THE CENTRAL REGION OF SÃO PAULO CITY. The chemical composition of rainwater samples collected from March 2002 to February 2003 in downtown São Paulo city (Universidade Presbiteriana Mackenzie) is presented. Potentiometric and conductimetric measurements were used to evaluate the $\left[\mathrm{H}^{+}\right]$and the total ionic content. Major anions and cations were determined by ion chromatography with conductivity detection. The rainwater was acidic with a mean $\mathrm{pH}$ of 4.99. The volume weighted means, VWM, of the anions nitrate, acetate and sulfate were, respectively, 21.2, 16.9 and

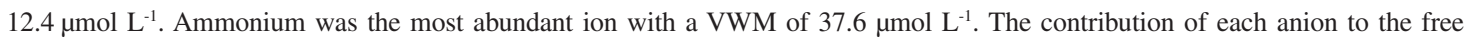
acidity potential decreases in the following order: $\mathrm{SO}_{4}{ }^{2-}(28.8 \%), \mathrm{CH}_{3} \mathrm{COO}^{-}(24.7 \%), \mathrm{NO}_{3}^{-}(22.8 \%), \mathrm{Cl}^{-}(13.4 \%), \mathrm{HCOO}^{-}(7.7 \%)$ and $\mathrm{C}_{2} \mathrm{O}_{4}{ }^{2-}(2.5 \%)$. The relative contribution of the weak organic acids to the free acidity was significant, $34.9 \%$.
\end{abstract}

Keywords: acid rain; ionic composition; air pollution.

\section{INTRODUÇÃo}

Considerado o principal pólo econômico do país e um dos maiores conglomerados humanos do mundo, a Região Metropolitana de São Paulo (RMSP) está cercada de problemas ambientais, sendo um deles a degradação da qualidade do ar, devida, principalmente, a emissões veiculares ${ }^{1-4}$.

No estado de São Paulo poluentes considerados chave para avaliação da qualidade do ar (partículas totais e inaláveis, fumaça, $\mathrm{SO}_{2}$, $\mathrm{NO}, \mathrm{NO}_{2}, \mathrm{CO}$ e $\mathrm{O}_{3}$ ) são monitorados pela Companhia de Tecnologia de Saneamento Ambiental (CETESB) ${ }^{1}$. No entanto, o mesmo não acontece com a precipitação, cujo conhecimento também é relevante, uma vez que a eficiência da remoção úmida de muitos poluentes resulta em impacto negativo nos mananciais, na biota e sobre os materiais expostos a essa deposição.

Em geral, para a caracterização química da deposição úmida atmosférica são priorizadas as medidas de $\mathrm{pH}$, condutividade, $\mathrm{SO}_{4}^{2-} \mathrm{e}$ $\mathrm{NO}_{3}$. Pesquisas mais detalhadas abrangem, $\mathrm{Cl}^{-}, \mathrm{NH}_{4}^{+}, \mathrm{Na}^{+}, \mathrm{K}^{+}, \mathrm{Ca}^{2+}$ e $\mathrm{Mg}^{2+} \mathrm{e}$, eventualmente, metais pesados e espécies orgânicas como ácidos carboxílicos ${ }^{5-10}$.

É importante destacar que em países da Europa e América do Norte existem programas de monitoramento envolvendo redes de amostragem cobrindo um ou mais países, obtendo-se avaliações tanto espaciais quanto temporais da composição química das águas de chuva e seus efeitos em diferentes ecossistemas (lagos, florestas e solos $)^{11-15}$. No Brasil, ao contrário do hemisfério norte, os dados disponíveis sobre deposição úmida originam-se de iniciativas isoladas ou de grupos de pesquisadores em algumas regiões e por períodos de tempo limitados ${ }^{10,16-29}$.

Na cidade de São Paulo, os primeiros estudos de caracterização química de águas de chuva foram realizados entre novembro/1983 e fevereiro/1985 e empregavam coleta manual (recipiente de coleta exposto no início do evento) em um único ponto de amostragem (zona oeste da cidade de São Paulo), com determinações de acidez

*e-mail: jpedrotti@mackenzie.com.br livre e acidez total. Neste período o valor médio registrado de $\mathrm{pH}$ das chuvas foi igual a 4,5, o que caracterizou o fenômeno da "chuva ácida"26.

Na mesma região da cidade, outro estudo mais sistemático e seletivo da deposição úmida empregou coletor automático de água de chuva e foi efetuado no período de novembro de 1988 e novembro de $1990^{27}$. Neste estudo, para 450 amostras de águas de chuva, verificou-se correlação entre a concentração de íons $\mathrm{H}^{+}$e a soma dos ânions $\mathrm{SO}_{4}^{2-}$ e $\mathrm{NO}_{3}^{-}$, assim como entre essas espécies e a condutividade. Além disso, este trabalho indicou os ácidos sulfúrico e nítrico como responsáveis pela acidez livre nessas precipitações, com valor médio de $\mathrm{pH}$ igual ao obtido no período de novembro de 1983 a fevereiro de 1985.

Por outro lado, resultados mais recentes da cidade de São Paulo (amostras coletadas no campus da Universidade de São Paulo - USP) mostraram a forte contribuição dos ácidos fórmico e acético para o valor da acidez livre de águas de chuva, variando de 10 a $70 \%$ para eventos individuais e atingindo $44 \%$ na média. A concentração média ponderada pelo volume (MPV) de formiato foi de $17,1 \mu \mathrm{mol} \mathrm{L} \mathrm{L}^{-1}$, a maior entre os ânions ${ }^{10}$.

No presente trabalho são mostrados resultados da determinação de $\mathrm{pH}$ e condutividade de amostras de águas de chuva coletadas na região central da cidade de São Paulo, campus da Universidade Presbiteriana Mackenzie (UPM), assim como a concentração dos íons majoritários $\left(\mathrm{Na}^{+}, \mathrm{NH}_{4}^{+}, \mathrm{K}^{+}, \mathrm{Ca}^{2+}, \mathrm{Mg}^{2+}, \mathrm{Cl}^{-}, \mathrm{NO}_{3}^{-}\right.$e $\left.\mathrm{SO}_{4}^{2-}\right)$ e ácidos carboxílicos (acético, fórmico e oxálico). Discutem-se, também, a contribuição dos ácidos orgânicos na acidez livre potencial e possíveis fontes de algumas das espécies estudadas.

\section{Descrição do ponto de amostragem}

Na RMSP, estima-se que 17 milhões de habitantes ocupam uma área de aproximadamente $8.000 \mathrm{~km}^{2}$, com cerca de 6 milhões de veículos e parque industrial com mais de 30.000 unidades $^{1}$. Na região, a dispersão dos poluentes é mais favorável nos meses de setembro a abril (verão quente e úmido) devido às condiçõos 
meteorológicas, caracterizadas por grande instabilidade associada a sistemas frontais vindos do sul do continente, que favorecem as ocorrências de eventos de chuva ${ }^{1}$. O ponto de amostragem localiza-se na região central de São Paulo (2332' S e 463' W) com intenso fluxo de veículos leves e pesados (principalmente ônibus) e está distante cerca de $80 \mathrm{~m}$ da Rua da Consolação.

\section{PARTE EXPERIMENTAL}

\section{Amostragem da água de chuva}

As amostragens de águas de chuva foram efetuadas com coletor automático para deposição úmida apenas ("wet-only") modelo G.K. Walter (Königsmoor, Alemanha) instalado no terraço do prédio da Faculdade de Tecnologia ( $15 \mathrm{~m}$ de altura) no campus da UPM. O funil do amostrador, posicionado a 1,5 $\mathrm{m}$ do piso, tem área de captação de $500 \mathrm{~cm}^{2}$. Os frascos coletores de $5,5 \mathrm{~L}$ de capacidade são alojados no interior do gabinete do amostrador, protegidos de radiação e outros tipos de intemperismos.

Assegurou-se a integridade das amostras lavando-se o funil do coletor automático, mensalmente, com solução de $\mathrm{HNO}_{3} 1 \%$ v/v, seguida de exaustivo enxágüe com água destilada e desionizada. Após cinco enxágües, foram utilizadas medidas de condutuvidade e de cromatografia de íons para avaliar a última porção da água de lavagem ("branco"). O funil foi considerado "limpo" quando as medidas de condutividade atingiram os valores correspondentes aos da água desionizada $\left(<1 \mu \mathrm{S} \mathrm{cm}^{-1}\right)$ e nenhum sinal foi observado nos cromatogramas correspondentes a esses brancos, tanto para cátions quanto para ânions. Desta maneira adotou-se, como prática, o mínimo de cinco enxágües com água desionizada após a limpeza com ácido nítrico.

Os frascos de polietileno de alta densidade também receberam limpeza similar à efetuada com o funil do coletor e foram mantidos com água desionizada até o momento do uso. Este procedimento garante a eliminação de qualquer excesso de íons $\mathrm{H}^{+}$e $\mathrm{NO}_{3}{ }^{-}$presentes das paredes dos frascos. As avaliações desta água utilizada no condicionamento ("brancos") por cromatografia de íons não indicaram a presença do íon nitrato ou qualquer outro íon, corroborando as medidas de condutividade. Somou-se ao procedimento descrito após a retirada da água desionizada, o uso de mais dois enxágües no momento da amostragem. Adicionalmente, cuidou-se para que os frascos recebessem mais dois enxágües com a própria amostra.

Logo após o término do evento de precipitação, ou no início da manhã (para eventos noturnos), o frasco de amostragem foi transferido para o laboratório. Em seguida, separam-se alíquotas para as diferentes determinações, que foram realizadas em no máximo dez dias após a coleta, mantendo-se as frações destinadas a medidas de $\mathrm{pH}$ e condutividade sob refrigeração $\left(4^{\circ} \mathrm{C}\right)$ ou congeladas $\left(-15^{\circ} \mathrm{C}\right)$ para as análises cromatográficas.

\section{Soluções e reagentes}

Todas as soluções foram preparadas com água desionizada obtida do sistema de purificação comercial Nanopure ${ }^{\circledR}$ (resistividade $>$ $18 \mathrm{M} \Omega \mathrm{cm}$ ). Os reagentes (Merck) utilizados foram de grau analítico. As soluções padrões foram preparadas instantes antes do uso. A vidraria e os recipientes para a armazenagem de soluções foram lavados com detergente, água destilada e ácido nítrico $1 \%$ v/v, seguido de intenso enxágüe com água desionizada.

\section{Instrumentação}

As medições diretas de $\mathrm{pH}$ foram feitas com potenciômetro
Digimed modelo DM-20. O eletrodo de vidro e o potenciômetro foram calibrados com solução de tampão $(\mathrm{pH}=6,85)$ de monohidrogenofosfato de potássio e di-hidrogenofosfato de potássio $0,05 \mathrm{~mol} \mathrm{~L}^{-1}$. A resposta nernstiana do eletrodo foi ajustada com solução tampão $(\mathrm{pH} 4,00)$ de biftalato ácido de potássio $0,05 \mathrm{~mol} \mathrm{~L}^{-1}$. Efetuou-se a correção do potencial de junção líquida residual do eletrodo de vidro, devido à baixa força iônica de amostras de águas de chuva, por meio da imersão do eletrodo de vidro em solução de ácido nítrico $1 \times 10^{-4} \mathrm{~mol} \mathrm{~L}^{-1}$ com valor de $\mathrm{pH}$ de 4,000 $\pm 0,005^{30}$. Todas as determinações de $\mathrm{pH}$, em triplicata, foram efetuadas com as amostras termostatizadas a $25 \pm 0,1^{\circ} \mathrm{C}$.

Empregou-se condutivímetro Digimed modelo DM-31 provido com célula de constante igual a $1,0 \mathrm{~cm}^{-1}$ para as medições de condutividade termostatizadas a $25 \pm 0,1^{\circ} \mathrm{C}$. A calibração do condutivímetro foi realizada com soluções padrão de cloreto de potássio nas concentrações de $10,1,0$ e 0,1 mmol L-1.

As análises cromatográficas foram feitas com sistema cromatográfico Metrohm modelo 761 e detecção condutométrica, sendo o controle da instrumentação e o tratamento das informações analíticas efetuados com o software Metrohm 761 PC V.1.1. Instantes antes do preenchimento do injetor, as amostras foram filtradas em membrana de policarbonato de $0,22 \mu \mathrm{m}$ de porosidade.

Para a determinação dos ânions utilizou-se coluna aniônica Metrosep A-Supp 4 (250 x $4 \mathrm{~mm}$ ) da Metrohm, como eluente solução tampão de $\mathrm{Na}_{2} \mathrm{CO}_{3} 1,8 \mathrm{mmol} \mathrm{L} \mathrm{m}^{-1} / \mathrm{NaHCO}_{3} 1,7 \mathrm{mmol} \mathrm{L} \mathrm{m}^{-1}$, vazão $1,0 \mathrm{~mL} \mathrm{~min}^{-1}$, volume injetado de $20 \mu \mathrm{L}$, coluna supressora Metrohm e como regenerante solução aquosa de $\mathrm{H}_{2} \mathrm{SO}_{4} 50 \mathrm{mmol} \mathrm{L}^{-1}$ sob vazão de $0,8 \mathrm{~mL} \mathrm{~min}^{-1}$. Nessas condições, os tempos de retenção dos ânions $\mathrm{CH}_{3} \mathrm{COO}^{-}, \mathrm{HCOO}^{-}, \mathrm{Cl}^{-}, \mathrm{NO}_{2}^{-}, \mathrm{NO}_{3}^{-}, \mathrm{SO}_{4}^{2-} \mathrm{e} \mathrm{C}_{2} \mathrm{O}_{4}^{2-}$ foram 4,8; 5,2; 6,$4 ; 7,5 ; 10,4 ; 17,7$ e $19,9 \mathrm{~min}$, respectivamente.

As condições analíticas para a determinação dos cátions foram coluna catiônica Metrosep modelo C2 250 (250 x 4 mm) da Metrohm, como eluente solução de ácido tartárico $4 \mathrm{mmol} \mathrm{L}^{-1}$ /ácido dipicolínico $0,75 \mathrm{mmol} \mathrm{L}^{-1}$ em $5 \%$ de acetona, volume injetado de $100 \mu \mathrm{L}$, vazão 1,0 mL min ${ }^{-1}$ e sistema de supressão eletrônico Metrohm. Os tempos de retenção para os cátions $\mathrm{Na}^{+}, \mathrm{NH}_{4}^{+}, \mathrm{K}^{+}, \mathrm{Ca}^{2+} \mathrm{e} \mathrm{Mg}^{2+}$ foram 8,9; 10,$1 ; 14,1 ; 21,1$ e 30,4 min, respectivamente.

As concentrações das espécies estudadas foram determinadas por meio de curva de calibração na faixa de concentração de 5 a $50 \mu \mathrm{mol} \mathrm{L} \mathrm{L}^{-1}$.

\section{RESULTADOS E DISCUSSÃO}

Entre março/2002 e fevereiro/2003, coletaram-se 94 amostras de águas de chuva, no campus da UPM. A partir de julho/2002 analisaram-se, além de $\mathrm{pH}$ e condutividade, as concentrações dos cátions e ânions majoritários, correspondentes a 78 amostras.

\section{Análises cromatográficas}

Os cromatogramas característicos de uma solução padrão de ânions contendo $50 \mu \mathrm{mol} \mathrm{L} \mathrm{L}^{-1}$ de cada espécie e de uma amostra de água de chuva (dia 31/01/2003) são apresentados nas Figuras 1a e 1 b.

As Figuras 2a e 2b ilustram os cromatogramas de uma solução

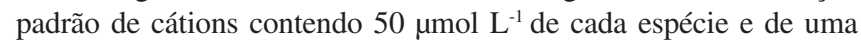
amostra de água de chuva coletada no dia 13/01/2003, respectivamente. Observa-se boa resolução dos picos e sensibilidade adequada para determinações simultâneas em amostras de águas de chuva das espécies aniônicas inorgânicas $\left(\mathrm{Cl}^{-}, \mathrm{NO}_{3}^{-}, \mathrm{SO}_{4}^{2-}\right.$ e $\left.\mathrm{NO}_{2}^{-}\right)$e orgânicas $\left(\mathrm{CH}_{3} \mathrm{COO}^{-}, \mathrm{HCOO}^{-}\right.$e $\left.\mathrm{C}_{2} \mathrm{O}_{4}^{2-}\right)$ e para os cátions $\left(\mathrm{Na}^{+}, \mathrm{NH}_{4}^{+}, \mathrm{K}^{+}, \mathrm{Ca}^{2+}\right.$ e $\mathrm{Mg}^{2+}$.

Os valores dos limites de detecção para os cátions e ânions, obtidos com sistema cromatográfico Metrohm 761, são apresentados 

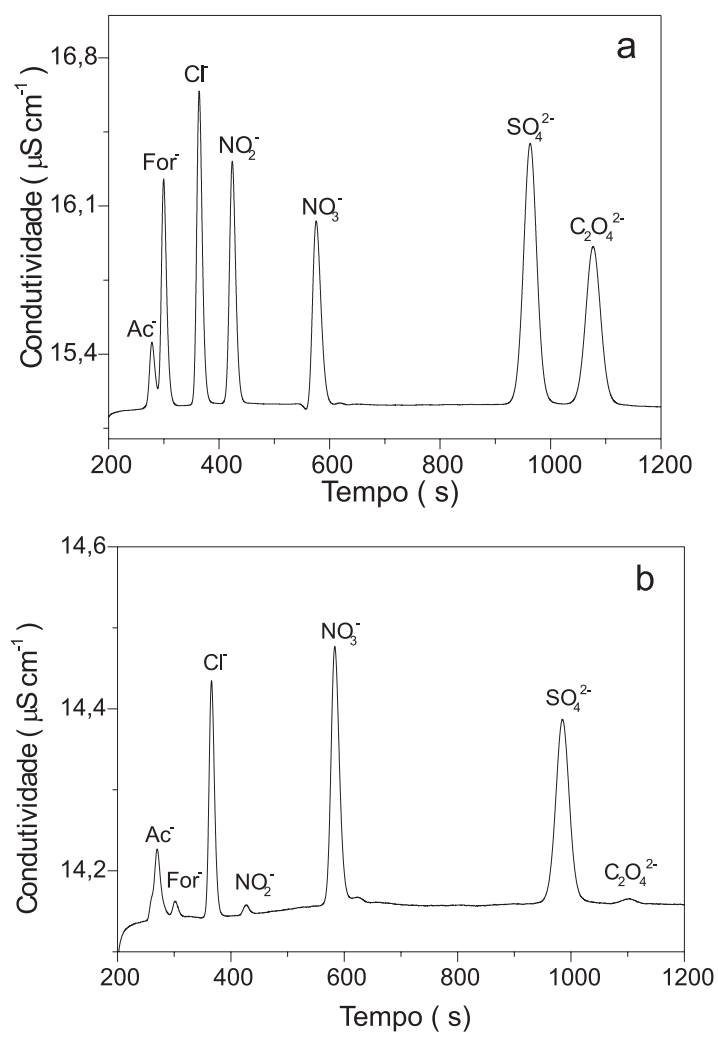

Figura 1. Cromatograma de ânions em solução padrão (a) contendo $50 \mu \mathrm{mol} L^{-1}$ de cada espécie e amostra de água de chuva coletada em 31/01/2003 (b). Coluna aniônica Metrosep A-Supp 4 (250 x 4 mm) da Metrohm, eluente solução de $\mathrm{Na}_{2} \mathrm{CO}_{3} 1,8 \mathrm{mmol} \mathrm{L}^{-1} / \mathrm{NaHCO}_{3} 1,7 \mathrm{mmol} \mathrm{L}^{-1}$, vazão 1,0 $\mathrm{mL} \mathrm{min}^{-1}$, volume injetado $20 \mu \mathrm{L}$, coluna supressora Metrohm e regenerante solução aquosa de $\mathrm{H}_{2} \mathrm{SO}_{4} 50 \mathrm{mmol} \mathrm{L}^{-1} \mathrm{sob}$ vazão de $0,8 \mathrm{~mL} \mathrm{~min}{ }^{-1}$

na Tabela 1. Estes valores foram calculados a partir dos parâmetros obtidos da análise, pelo método dos mínimos quadrados, da curva de calibração $(\mathrm{y}=\mathrm{a}+\mathrm{bx})$ e correspondem ao sinal do branco (ou coeficiente linear) mais 3 vezes o desvio padrão do "branco" $\left(\mathrm{s}_{\mathrm{y} / \mathrm{x}}\right)$, ou seja, $L D=a+3 s_{y / x}{ }^{31}$.

Tabela 1. Valores de limites de detecção obtidos por cromatografia de íons com detecção condutométrica para cátions e ânions

\begin{tabular}{cc}
\hline Íon & Limite detecção $\left(\mu \mathrm{mol} \mathrm{L}^{-1}\right)$ \\
\hline $\mathrm{Na}^{+}$ & 0,8 \\
$\mathrm{NH}_{4}^{+}$ & 0,6 \\
$\mathrm{~K}^{+}$ & 0,5 \\
$\mathrm{Ca}^{2+}$ & 1,3 \\
$\mathrm{Mg}^{2+}$ & 2,4 \\
$\mathrm{CH}_{3} \mathrm{COO}^{-}$ & 0,3 \\
$\mathrm{HCOO}^{-}$ & 0,4 \\
$\mathrm{Cl}^{-}$ & 0,8 \\
$\mathrm{NO}_{2}^{-}$ & 0,4 \\
$\mathrm{NO}_{3}^{-}$ & 0,5 \\
$\mathrm{SO}_{4}^{2-}$ & 0,6 \\
$\mathrm{C}_{2} \mathrm{O}_{4}^{2-}$ & 0,5 \\
\hline
\end{tabular}

Validação dos resultados: balanço iônico e comparação entre condutividade medida e calculada

A validação dos resultados das análises de água de chuva foi
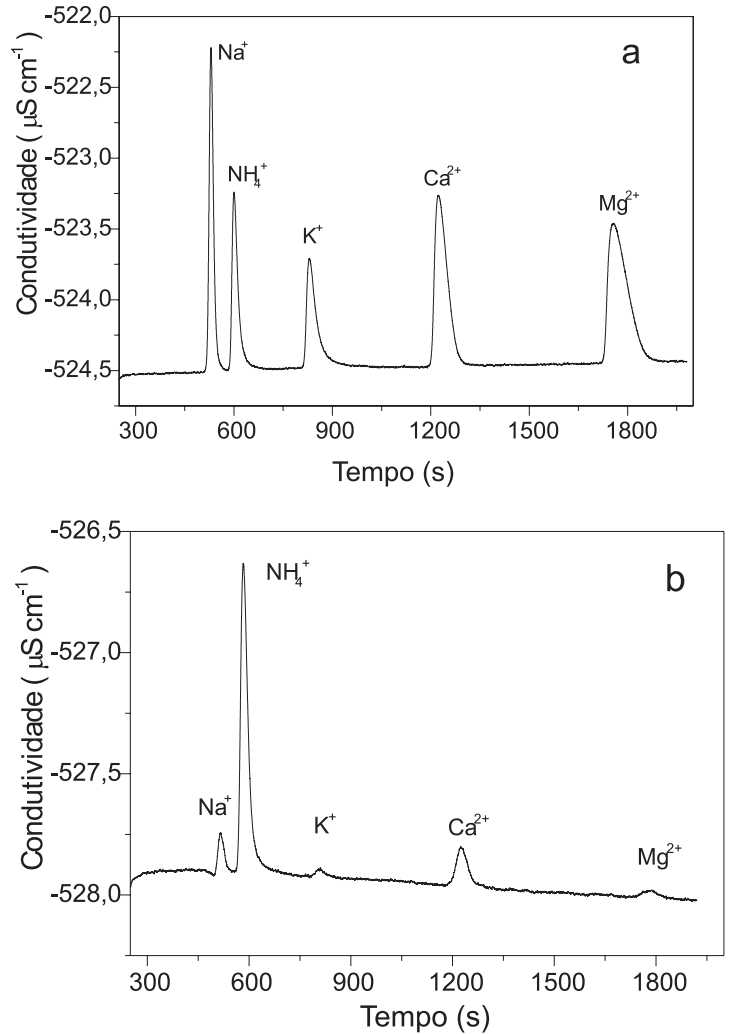

Figura 2. Cromatograma de cátions de solução padrão (a) contendo $50 \mu \mathrm{mol} \mathrm{L^{-1 }}$ de cada espécie e amostra de água de chuva coletada em 13/01/2003 (b). Coluna Metrosep C2 250 (250 x 4 mm), eluente 4 mmol L-1 em ácido tartárico, $0,75 \mathrm{mmol} \mathrm{L}^{-1}$ em ácido dipicolínico e acetona $5 \%$;

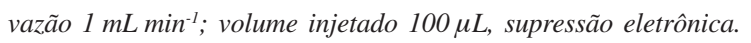

feita obedecendo a dois critérios: a) condição de eletroneutralidade (balanço de cargas) e b) comparação entre os valores de condutância medidos $\left(\Lambda_{\text {med }}\right)$ e calculados $\left(\Lambda_{\text {cal }}\right)$ para cada amostra. As diferenças iônicas podem variar de 10 a $60 \%$, dependendo do teor iônico total, possibilitando indicar amostras que podem ser rejeitadas ${ }^{32}$. Seguindo esses critérios rejeitaram-se 9 amostras $(11,5 \%)$ para as avaliações ambientais discutidas a seguir.

O balanço iônico considera o produto das cargas pela concentração ( $\mu$ eq $\mathrm{L}^{-1}$ ) de cada íon, $c_{i} z_{i}$. Se todas as espécies iônicas majoritárias presentes na amostra foram analisadas, a soma das cargas dos cátions deve ser igual à dos ânions. Assim, o balanço iônico pode ser estimado de acordo com as equações ${ }^{32}$ :

$$
\begin{aligned}
\sum_{\text {cátions }}= & {\left[\mathrm{H}^{+}\right]+\left[\mathrm{NH}_{4}^{+}\right]+\left[\mathrm{Na}^{+}\right]+\left[\mathrm{K}^{+}\right]+\left[\mathrm{Ca}^{2+}\right]+\left[\mathrm{Mg}^{2+}\right] } \\
\sum_{\text {ânions }}= & {\left[\mathrm{Cl}^{-}\right]+\left[\mathrm{NO}_{3}^{-}\right]+\left[\mathrm{NO}_{2}^{-}\right]+\left[\mathrm{CH}_{3} \mathrm{COO}^{-}\right]+\left[\mathrm{HCOO}^{-}\right]+\left[\mathrm{SO}_{4}^{2-}\right]+} \\
& {\left[\mathrm{C}_{2} \mathrm{O}_{4}^{2-}\right] }
\end{aligned}
$$

A concentração hidrogeniônica livre $\left(\mathrm{H}^{+}\right)$considerada para o cálculo da soma de cátions foi obtida através da conversão do valor do $\mathrm{pH}$ de cada amostra. No somatório dos ânions foram consideradas as espécies inorgânicas e orgânicas, assumindo a dissociação completa dos ácidos acético $\left(\mathrm{K}_{\mathrm{a}}=1,76 \times 10^{-5} \mathrm{~mol} \mathrm{~L}^{-1}\right)$, fórmico $\left(\mathrm{K}_{\mathrm{a}}=1,77 \mathrm{x}\right.$ $\left.10^{-4} \mathrm{~mol} \mathrm{~L}^{-1}\right)$ e oxálico $\left(\mathrm{K}_{\mathrm{a} 1}=5,6 \times 10^{-2} \mathrm{~mol} \mathrm{~L}^{-1}\right.$ e $\mathrm{K}_{\mathrm{a} 2}=5,42 \times 10^{-5} \mathrm{~mol}$ $\left.\mathrm{L}^{-1}\right)^{2-3}$. Cabe mencionar que, cálculos mais refinados demonstraram que no conjunto de amostras investigadas por cromatografia de íons ( $\mathrm{pH}$ médio = 4,99), a fração de íons HCOO- livre corresponde a 95\%, enquanto a fração ionizada de $\mathrm{CH}_{3} \mathrm{COO}^{-}$corresponde a $63 \%$. 
O gráfico que relaciona o balanço de cátions e ânions (Figura 3a) demonstra excelente correlação no conjunto de dados $(r=0,97)$ e boa distribuição em torno da correlação ideal (linha contínua). A Figura $3 \mathrm{~b}$ apresenta o gráfico dos valores da $\Lambda_{\text {calc }}$ em relação a $\Lambda_{\text {med }}$ $(\mathrm{r}=0,98)$. Esses resultados indicam que as espécies iônicas investigadas por cromatografia de íons além da concentração de $\mathrm{H}^{+}$, obtida por meio de medidas potenciométricas de $\mathrm{pH}$, compõem as espécies majoritárias nas amostras de água de chuva investigadas na região central de São Paulo.
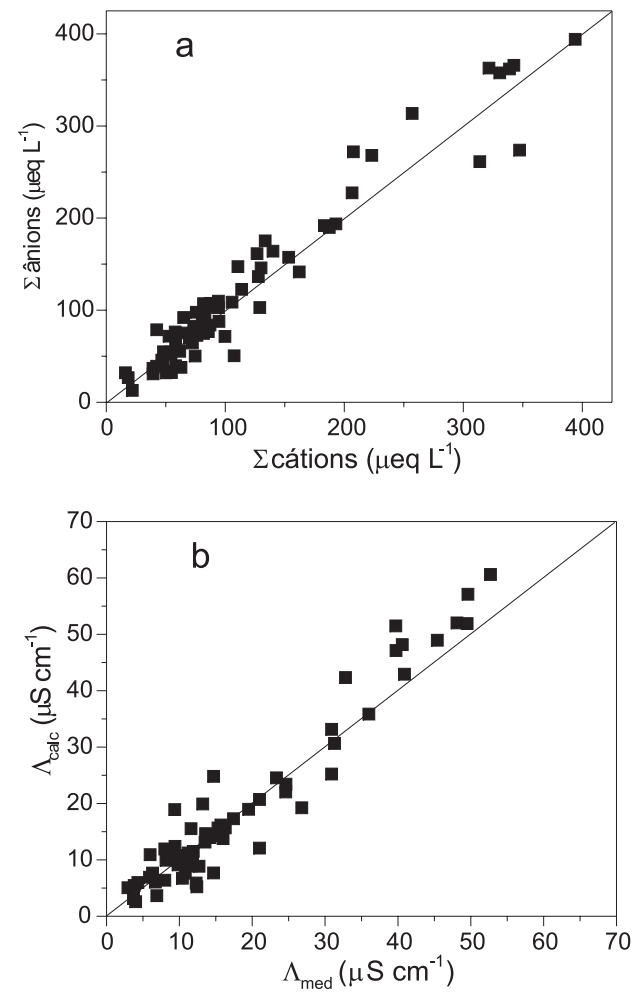

Figura 3. Balanço iônico nas amostras $(n=69)$ de água de chuva (a) e correlação entre os valores de condutância medidos e calculados (b). A linha contínua refere-se à correlação ideal e ao coeficiente angular unitário.

\section{Composição química da água de chuva}

O gráfico tipo "box-whisker" foi utilizado para expressar o intervalo das concentrações dos cátions e ânions majoritários, conforme ilustram as Figuras $4 a$ e $4 b$.

Outra forma de apresentação das concentrações iônicas em águas de chuva é a média ponderada pelo volume (MPV), cuja importância é limitar a influência de concentrações muito altas que ocorrem em chuvas muito fracas, assim como efeitos de diluição em chuvas muito intensas. O cálculo de MPV para as diferentes espécies de concentração $[X]$, analisadas nas $n$ amostras de águas de chuva com volume $V$ cada $\mathrm{e}^{32}$ :

$[X]_{M P V}=\frac{\sum_{i=1}^{n}[X]_{i} V_{i}}{\sum_{i=1}^{n} V_{i}}$

Valores das concentrações MPV e médias aritméticas ( \pm desvio padrão) $)^{31}$, assim como da deposição $\left(\mathrm{mg} \mathrm{m}^{-2}\right.$ mês $\left.^{-1}\right)$ para as espécies analisadas em águas de chuva da região central de São Paulo estão apresentados na Tabela 2. Utilizou-se a quantidade de chuva calculada através dos volumes de cada amostra e da área correspondente
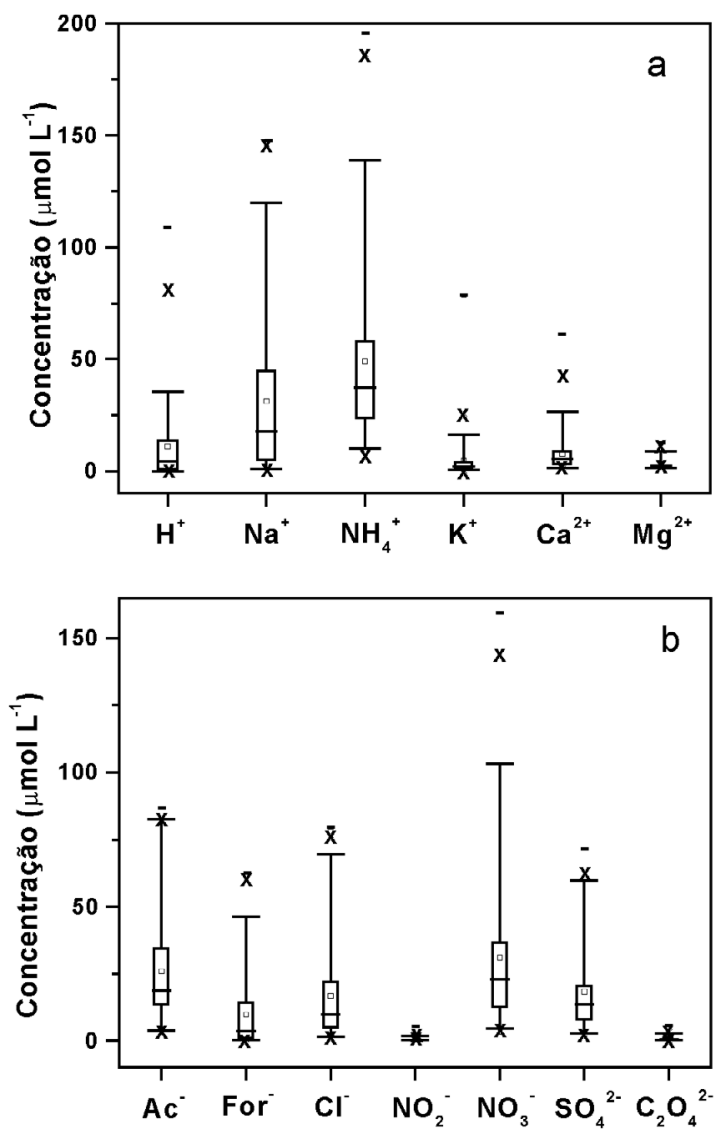

Figura 4. Gráfico tipo "box-whisker" das concentrações dos cátions (a) e dos ânions (b) em amostras de águas de chuva de São Paulo, entre julho/ 2002 e fevereiro/2003. As linhas horizontais da caixa expressam os valores de 25, 50 e 75\%. A barra de erro inclui os valores entre 5 e 95\%; (x) os valores correspondentes a 1 e $99 \%$ e o sinal (-) os valores mínimo e máximo do conjunto de dados. A média aritmética corresponde ao $\square$ dentro da caixa

Tabela 2. Concentração e deposição das espécies químicas analisadas em amostras de águas de chuva na região central de São Paulo: média ponderada por volume (MPV) e média aritmética ( \pm desvio padrão) 94 amostras para $\mathrm{pH}$ e condutividade (03/2002-02/2003) e 69 amostras para cátions e ânions (07/2002-02/2003)

\begin{tabular}{cccc}
\hline Ín & MPV & $\begin{array}{c}\text { Média }( \pm d p) \\
\mu m o l ~ L^{-1}\end{array}$ & $\begin{array}{c}\text { deposição } \\
\mathrm{mg} \mathrm{m}^{-2} \text { mês }^{-1}\end{array}$ \\
\hline $\mathrm{CH}_{3} \mathrm{COO}^{-}$ & 16,9 & $25,9(20,9)$ & 103 \\
$\mathrm{HCOO}^{-}$ & 4,69 & $9,77(14,6)$ & 22 \\
$\mathrm{Cl}^{-}$ & 8,54 & $16,7(18,7)$ & 31 \\
$\mathrm{NO}_{2}^{-}$ & 0,46 & $0,59(0,71)$ & 2,2 \\
$\mathrm{NO}_{3}^{-}$ & 21,2 & $30,9(30,7)$ & 136 \\
$\mathrm{SO}_{4}^{2-}$ & 12,4 & $18,2(16,3)$ & 124 \\
$\mathrm{C}_{2} \mathrm{O}_{4}^{2-}$ & 0,63 & $0,86(0,91)$ & 5,5 \\
$\mathrm{Na}^{+}$ & 15,0 & $31,3(36,0)$ & 35 \\
$\mathrm{NH}_{4}^{+}$ & 37,6 & $49,0(40,3)$ & 70 \\
$\mathrm{~K}^{+}$ & 2,64 & $4,54(10,1)$ & 10 \\
$\mathrm{Ca}^{2+}$ & 5,33 & $7,89(9,85)$ & 22 \\
$\mathrm{Mg}^{2+}$ & 2,51 & $2,89(2,11)$ & 6,2 \\
$\mathrm{H}^{+}$ & 6,51 & $10,1(16,4)$ & 0,63 \\
$\mathrm{pH}^{-}$ & 5,19 & 4,99 & - \\
$\left(\mu \mathrm{Sm}^{-1}\right)$ & 13,0 & $18,7(12,6)$ & - \\
\hline
\end{tabular}


do funil de amostragem para a estimativa da deposição. Neste estudo analisou-se $1050 \mathrm{~mm}$ de chuva referentes a $100 \%$ dos eventos de deposição úmida do período na região.

\section{Íons inorgânicos}

Os resultados apresentados na Tabela 2 e Figura 4 mostram grandes variações das concentrações das espécies analisadas nas águas de chuva no centro de São Paulo. Essas variações de concentração também foram observadas em estudos anteriores realizados na região oeste da cidade de São Paulo (campus da USP) $)^{10,17}$.

Os resultados da concentração dos íons cloreto e sódio do presente estudo foram espécies que apresentaram algumas diferenças em relação aos trabalhos realizados anteriormente em São Paulo. Por exem-

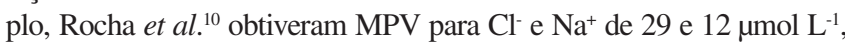
respectivamente, e consideraram todo sódio e $50 \%$ do cloreto como de origem marinha, para o período de 1997-1998 na região oeste de São Paulo. O íon sódio é muitas vezes usado como elemento de referência, assumindo-se que o mesmo é de origem marinha e, a partir das razões molares desse íon com cloreto, sulfato, cálcio e magnésio nas águas dos oceanos, calcula-se a contribuição marinha para a concentração desses íons nas amostras de águas de chuva. Porém, na literatura, há alguns estudos em que se observou predominância do sódio em relação ao cloreto, os autores consideraram essa última espécie como indicadora de fonte marinha ${ }^{18}$. Forti $\mathrm{el} \mathrm{al} .{ }^{17}$ descrevem que a dificuldade de se identificar e quantificar fontes de sódio em centros urbanos e a falta de outros elementos de referência conduz à adoção do sódio como traçador da contribuição marinha.

Considerando as questões acima e a partir da razão $\mathrm{Na}^{+} / \mathrm{Cl}^{-}=$ 1,75 obtida no presente estudo, que está fora da faixa de $0,5-1,5$ recomendada pelo Grupo de Estudos de Poluição do Ar da União Européria $^{32}$ para indicar fonte marinha, decidiu-se não considerar como única fonte do sódio a brisa marinha. Apesar da alta correlação (Tabela 3 ) entre sódio e cloreto $(r=0,94)$, considerou-se o cloreto e também os íons sulfato, cálcio e magnésio como espécies de origem predominantemente continental/antropogênica.

A Tabela 2 e Figura 4 mostram predominância significativa do amônio em relação às outras espécies iônicas dissolvidas nas águas de chuva da região central de São Paulo. A concentração do íon amônio também foi significativa em relação às outras espécies iônicas nas águas de chuva anteriormente estudadas na cidade de São Pau$10^{10,17}$. Em geral, na literatura encontra-se que para $\mathrm{NH}_{3} / \mathrm{NH}_{4}^{+}$as fontes atmosféricas consideradas importantes são as emissões biogênicas relacionadas à decomposição de matéria orgânica (lixo, esgoto), eliminação metabólica (incluindo humanos e animais em geral), agropecuária intensiva e queima de biomassa (atividades agrícolas e incêndios florestais). Enquanto que, para ambientes urbanos e/ou industrializados, além dessas fontes, para amônio em águas de chuva têm-se contribuições de dissolução de partículas de $\left(\mathrm{NH}_{4}\right)_{2} \mathrm{SO}_{4}$ e/ ou $\mathrm{NH}_{4} \mathrm{NO}_{3}{ }^{17}$.

Por outro lado, $\mathrm{NH}_{3}$ não consta entre as espécies consideradas importantes para a avaliação de qualidade de ar e existem poucos estudos relacionados a essa espécie gasosa em centros urbanos. Estudos para avaliação dos inventários de emissão para compostos de nitrogênio e especificamente para amônia começam a considerar as emissões devido à queima de combustíveis fósseis ${ }^{33-36}$. Resultados iniciais mostraram que carros equipados com catalisadores de três vias podem emitir até 60 vezes mais amônia por km rodado quando comparados a veículos sem este dispositivo ${ }^{33}$. Portanto, não se deve descartar a possibilidade de que as altas concentrações de amônio nas águas de chuva do centro de São Paulo podem estar relacionadas ao intenso tráfego de veículos da região, somadas às contribuições das emissões metabólicas ${ }^{33}$, lembrando que a estimativa da popula- ção da RMSP é de 17 milhões de pessoas ${ }^{1}$, além dos animais domésticos e dos ratos.

Tabela 3. Matriz de correlação entre algumas espécies iônicas determinadas em águas de chuva, amostradas na região central de São Paulo, entre julho/2002 e fevereiro/2003

\begin{tabular}{lcccc}
\hline & $\mathrm{NO}_{3}{ }^{-}$ & $\mathrm{CH}_{3} \mathrm{COO}^{-}$ & $\mathrm{SO}_{4}^{2-}$ & $\mathrm{Cl}^{-}$ \\
\hline $\mathrm{NH}_{4}^{+}$ & $\mathbf{0 , 8 3}$ & 0,56 & $\mathbf{0 , 7 6}$ & 0,49 \\
$\mathrm{Na}^{+}$ & 0,53 & 0,51 & 0,62 & $\mathbf{0 , 9 4}$ \\
$\mathrm{Ca}^{2+}$ & $\mathbf{0 , 8 5}$ & 0,56 & $\mathbf{0 , 7 1}$ & 0,41 \\
$\mathrm{Mg}^{2+}$ & $\mathbf{0 , 7 9}$ & 0,57 & 0,57 & 0,43 \\
$\mathrm{H}^{+}$ & 0,26 & 0,24 & 0,44 & 0,24 \\
\hline
\end{tabular}

Seguido ao amônio, a segunda espécie em abundância nas águas de chuva do centro de São Paulo foi o íon nitrato (Tabela 2 e Figura 4). Íons nitrato em águas de chuva, de centros urbanos como São Paulo, são provenientes predominantemente da oxidação de óxidos de nitrogênio $\left(\mathrm{NO}_{x}=\mathrm{NO}+\mathrm{NO}_{2}\right)$ emitidos pela queima de combustíveis fosseis usados na frota veicular ${ }^{1}$. Segundo dados do inventário de emissões relativas de poluentes para a RMSP, $96 \%$ do $\mathrm{NO}_{x}$ são emitidos pela frota de veículos (6 milhões de unidades), sendo $81 \%$ referentes a motores a diese $l^{1}$. A presença significativa de nitrato nas águas de chuva do centro de São Paulo indica a importância dos processos de remoção úmida para essa espécie, concordando com os dados do relatório anual da rede de monitoramento de qualidade do ar da CETESB que mostram que tanto o material particulado quanto os $\mathrm{NO}_{\mathrm{x}}$ estão presentes em concentrações significativas na atmosfera da cidade de São Paulo ${ }^{1}$.

Ainda em relação aos ânions, destaca-se a significativa concentração do sulfato nas águas de chuva de São Paulo (Tabela 2), cuja fonte principal é a oxidação de S(IV) emitido pela queima de combustíveis. Apesar do controle das fontes de $\mathrm{SO}_{2}$ desde o início da década de 80, tanto das emissões veiculares quanto dos processos industriais na RMSP, ainda se observa concentração atmosférica média anual de $\mathrm{SO}_{2}$ na faixa de $20 \mu \mathrm{g} \mathrm{m}^{-3}$ nos últimos 5 anos $^{1}$.

Os cátions $\mathrm{Ca}^{2+}, \mathrm{Mg}^{2+}$ e $\mathrm{K}^{+}$em centros urbanos são, em geral, associados à ressuspensão de poeira de solo, assim como às atividades da construção civil ${ }^{17}$. Apesar de suas concentrações baixas em relação aos outros íons, são importantes na contribuição iônica majoritária nas águas de chuva da região central da cidade de São Paulo.

\section{Íons orgânicos}

Os ácidos orgânicos que predominam em amostras de águas de chuva em diversas partes do mundo são os ácidos monocarboxílicos, fórmico (For-) e acético $\left(\mathrm{Ac}^{-}\right)$. Entre os ácidos dicarboxílicos, o ácido oxálico é o mais freqüentemente encontrado ${ }^{37}$. Estudo efetuado com 60 amostras de água de chuva na região urbana da cidade de Los Angeles, com intensa frota veicular, revelou concentração média de $\mathrm{H}_{2} \mathrm{C}_{2} \mathrm{O}_{4}$ de $6,5 \mu \mathrm{mol} \mathrm{L} \mathrm{L}^{-1}$, com ocorrência em $100 \%$ das amos$\operatorname{tras}^{37}$.

No presente estudo, além dos ácidos acético e fórmico, o ácido oxálico tem ocorrido em $74 \%$ dos eventos avaliados, com concentração máxima de $7,1 \mu \mathrm{mol} \mathrm{L}{ }^{-1}$, valor similar ao quantificado por Kawamura e colaboradores ${ }^{37}$.

Estudos de amostras de material particulado e fase gasosa efetuados em túnel em São Paulo permitiram detectar, além dos ácidos fórmico e acético, ácido oxálico e outros ácidos carboxílicos em menor concentração ${ }^{38}$. Os resultados destes estudos mostraram a importância da emissão veicular, sendo predominante o ácido acético em relação ao ácido fórmico ${ }^{38}$. 
A relação entre os ácidos acético e fórmico na fase gasosa e/ou líquida da atmosfera tem sido utilizada como parâmetro da indicação da importância relativa de emissões diretas (poluentes primários) ou produtos de reações químicas na atmosfera (poluentes secundários). A relação For $/ \mathrm{Ac}^{-<1}<$, é indicativa da predominância de ácido acético devido à emissão direta por emissão biogênica e, principalmente, queima de combustíveis, levando-se em conta o local de amostragem. A relação For $/ \mathrm{Ac}^{-}>1$ indica predominância da formação de ácidos carboxílicos (ácido fórmico) através de reações fotooxidativas na atmosfera ${ }^{10,37,38}$.

Comparando-se os resultados do presente trabalho com determinações anteriores efetuadas na Cidade Universitária - com predominância do ácido fórmico $\left(17,1 \mu \mathrm{mol} \mathrm{L} \mathrm{L}^{-1}\right)$ em relação ao acético $\left(9,0 \mu \mathrm{mol} \mathrm{L}{ }^{-1}\right)^{10}$ - observou-se situação inversa na região central, com a razão For $/ A c c^{-}<1$, ácidos acético $16,9 \mu \mathrm{mol} \mathrm{L} \mathrm{L}^{-1}$ e fórmico $4,69 \mu \mathrm{mol} \mathrm{L} \mathrm{L}^{-1}$, indicando predominância das emissões diretas, reflexo de maior densidade de fluxo veicular no centro de São Paulo.

Apesar das diferenças de períodos, locais de amostragem e metodologia analítica, a comparação entre os resultados do presente trabalho com esses estudos anteriores indica similaridades entre as concentrações das espécies iônicas majoritárias das amostras de águas de chuva de São Paulo. Sendo que, as diferenças observadas demonstram a importância de fontes locais contribuindo para a composição iônica, devido a processos de remoção de poluentes abaixo da nuvem durante o evento de precipitação. Outro fator importante a ser considerado para a avaliação da composição química de águas de chuva são as condições meteorológicas como direção e intensidade de ventos, temperatura, umidade relativa, taxa de precipitação e tamanho médio de gotas de chuva. Portanto, a discussão mais detalhada comparando-se os resultados entre os diferentes estudos de composição química de águas de chuva em São Paulo necessita de informações adicionais não disponíveis, como dados meteorológicos.

\section{Acidez da água de chuva}

As medidas de $\mathrm{pH}$ foram efetuadas em 94 amostras com volumes que variaram de $40 \mathrm{~mL}$ a 5,5 L. A Figura 5 apresenta o histograma dos valores de $\mathrm{pH}$ para todas as amostras de águas de chuva do período. Nesse conjunto, $55 \%$ das amostras apresentaram valores de $\mathrm{pH}$ $<5,6$ (resultante do equilíbrio da água pura com o $\mathrm{CO}_{2}$ atmosférico), limite considerado na caracterização do fenômeno da chuva ácida. O valor médio de $\mathrm{pH}=4,99$ e a MPV = 5,19 encontram-se no limite superior da faixa de valores de estudos anteriores (região oeste campus da USP), que apresentaram média de $\mathrm{pH}$ entre 4,5 e $5,0^{10,17-19,26,27}$.

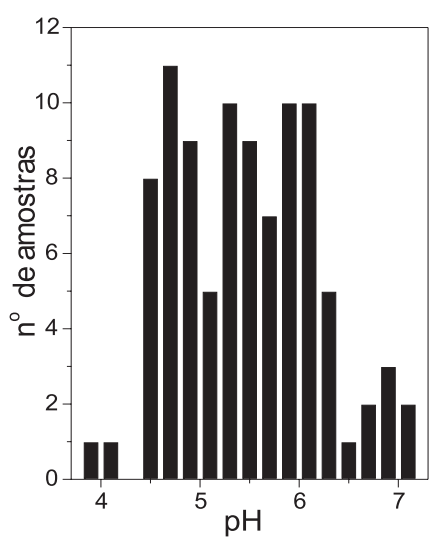

Figura 5. Histograma dos valores de pH para as amostras de águas de chuva coletadas na região central de São Paulo, entre março/2002 e fevereiro/2003
A Figura 6 mostra a comparação, correspondente ao período de 12 meses, entre as MPV mensais dos valores de $\mathrm{pH}$ com as médias de condutividade, juntamente com os volumes mensais de chuva. Nos meses de dezembro, janeiro e fevereiro observaram-se os menores valores das médias de condutividade (menor teor iônico), mostrando o processo de "limpeza" da atmosfera nos períodos chuvosos, além do efeito de diluição. Sendo $\mathrm{H}^{+} \mathrm{o}$ íon de maior contribuição para as medidas de condutividade destaca-se, pela Figura 6, a relação inversa entre os valores de $\mathrm{pH}$ e condutividade. Porém, em meses com menor índice pluviométrico, durante o inverno, as concentrações de $\mathrm{H}^{+}$contribuíram menos para as medidas de condutividade, que pode ser explicado pela predominância relativa de espécies com capacidade neutralizante, como amônia e carbonatos/hidróxidos de cálcio.

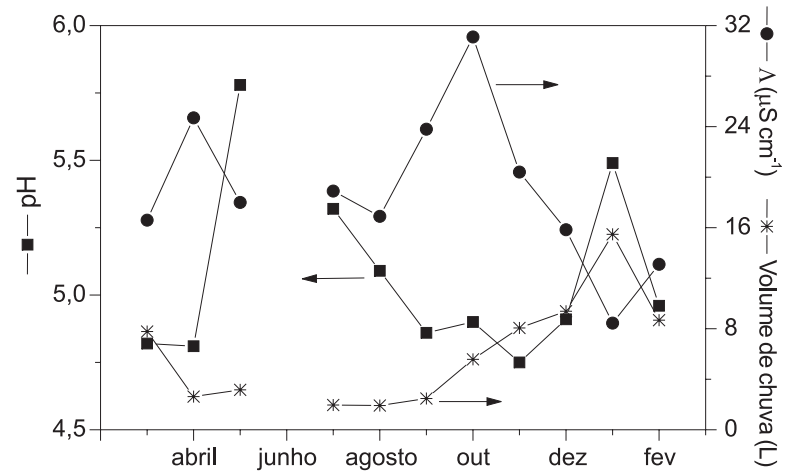

Figura 6. Perfil mensal das médias dos valores de $\mathrm{pH}$ e da condutividade, juntamente com o volume de chuva para as amostras de águas de chuva da região central de São Paulo, entre março/2002 e fevereiro/2003. Em junho/ 2002 não ocorreu nenhum evento de chuva

Estes resultados indicam que somente medidas de acidez livre na deposição úmida não são suficientes para caracterizar problemas de poluição do ar, mostrando a importância da avaliação da composição iônica majoritária de águas de chuva. Se se considerar que todos os ânions $\left(\mathrm{Cl}^{-}, \mathrm{NO}_{3}^{-}, \mathrm{CH}_{3} \mathrm{COO}^{-}, \mathrm{HCOO}^{-}, \mathrm{SO}_{4}^{2-}, \mathrm{C}_{2} \mathrm{O}_{4}^{2-}\right)$ existissem apenas na forma de ácidos livres e lembrando que sulfato e oxalato são ânions de ácidos dipróticos, a soma das MPV dessas espécies resultaria em solução com $\mathrm{pH}=4,1$, diferente do resultado experimental de 5,19. A contribuição relativa de cada ânion na acidez livre potencial (ALP) das amostras de água de chuva foi estimada através da equação:

\section{$\% \mathrm{ALP}=[\mathrm{X}] / \Sigma$ ânions}

onde $[\mathrm{X}]$ é a concentração MPV $\left(\mu \mathrm{mol} \mathrm{L} \mathrm{L}^{-1}\right)$ do ânion multiplicada pelo número de átomos de hidrogênio ionizável,

$$
\begin{aligned}
\Sigma \text { ânions }= & {\left[\mathrm{Cl}^{-}\right]+\left[\mathrm{NO}_{3}^{-}\right]+\left[\mathrm{CH}_{3} \mathrm{COO}^{-}\right]+\left[\mathrm{HCOO}^{-}\right]+2 \times\left[\mathrm{SO}_{4}^{2-}\right]+} \\
& 2 \mathrm{x}\left[\mathrm{C}_{2} \mathrm{O}_{4}^{2-}\right]
\end{aligned}
$$

A Tabela 4 contempla a participação relativa dos ácidos orgânicos e inorgânicos nas amostras de água de chuva no sítio da UPM. Verifica-se que a participação dos ácidos inorgânicos é superior (65,0\%), enquanto que os ácidos carboxílicos têm participação de 34,9\%. Em relação aos ácidos orgânicos, esta taxa é similar à obtida por Kawamura et al. ${ }^{37}$, no período de 1984 a 1987 na cidade de Los Angeles, EUA, mas $10 \%$ inferior ao obtido por Fornaro e Gutz ${ }^{10}$, no sítio de amostragem da Cidade Universitária (Instituto de Química USP), no período de fevereiro a outubro de 2000.

Na Tabela 2 destacam-se as concentrações de amônio e de cálcio como indicadores da incorporação de compostos neutralizantes, re- 
Tabela 4. Contribuição dos ácidos orgânicos e inorgânicos no potencial de acidez livre das águas de chuva no sítio da UPM

\begin{tabular}{cc}
\hline Espécie & $\%$ ALP \\
\hline $\mathrm{CH}_{3} \mathrm{COOH}$ & 24,7 \\
$\mathrm{HCOOH}$ & 7,7 \\
$\mathrm{HCl}$ & 13,5 \\
$\mathrm{HNO}_{3}$ & 22,8 \\
$\mathrm{H}_{2} \mathrm{SO}_{4}$ & 28,7 \\
$\mathrm{H}_{2} \mathrm{C}_{2} \mathrm{O}_{4}$ & 2,5 \\
\hline
\end{tabular}

forçado pelas altas correlações desses cátions com nitrato e sulfato mostradas na Tabela 3. Estes resultados indicam a importância da presença de espécies como $\mathrm{NH}_{3}$ e carbonatos/hidróxidos de cálcio, com capacidade de neutralizar a acidez livre potencial.

\section{CONCLUSÕES}

Determinou-se a composição iônica de amostras de águas de chuva entre março/2002 e fervereiro/2003 na região central de São Paulo. O valor médio de $\mathrm{pH}$ no período foi 4,99 (MPV, $\mathrm{pH}=5,19$ ). Entre os ânions, a contribuição de $\mathrm{NO}_{3}^{-}$foi levemente superior a $\mathrm{CH}_{3} \mathrm{COO}^{-}$, seguido de $\mathrm{SO}_{4}^{2-}, \mathrm{Cl}^{-}$e $\mathrm{HCOO}^{-}$. Além disso, observou-se predominância de $\mathrm{NH}_{4}^{+}$, seguida de $\mathrm{Na}^{+}$e $\mathrm{H}^{+}$. Os resultados mostraram a importância de espécies como amônia na neutralização da acidez das águas de chuva, através da alta concentração de $\mathrm{NH}_{4}^{+}$ $\left(49,0 \pm 40,3 \mu \mathrm{mol} \mathrm{L}{ }^{-1}\right)$. A avaliação da acidez livre potencial demonstrou a contribuição significativa dos ácidos orgânicos (34,9\%). A importância da emissão veicular também foi demonstrada mediante as concentrações dos ácidos carboxílicos, com predominância do ácido acético em relação ao fórmico. Apesar da baixa concentração do íon $\mathrm{NO}_{2}^{-}$, sua presença foi forte indicativo de reatividade do meio, ou seja, de processos oxidativos ainda ocorrendo na fase aquosa durante o evento de precipitação na região central de São Paulo.

\section{AGRADECIMENTOS}

Os autores agradecem à FAPESP (processo $n^{\circ}$. 01/09838-0) e ao MACKPESQUISA pelo auxílio financeiro. Ao Instituto de Tecnologia para o Desenvolvimento do Paraná - LACTEC - pelo empréstimo do coletor automático de água de chuva.

\section{REFERÊNCIAS}

1. CETESB - Relatório de Qualidade do Ar no Estado de São Paulo - 2002, Secretaria do Meio Ambiente, Série Relatórios - ISSN 0103-4103, São Paulo, 2003; http://www.cetesb.sp.gov.br, acessada em Janeiro 2004.

2. Finlayson-Pitts, B. J.; Pitts Jr., J. N.; Atmospheric Chemistry: Fundamentals and Experimental Techniques, John Wiley \& Sons: New York, 1986.

3. Seinfeld, J. H.; Pandis, S. N.; Atmospheric Chemistry and Physics of Air Pollution, John Wiley: New York, 1998.

4. Godish, T.; Air Quality, $3^{\text {rd }}$ ed., Lewis Publishers: Boca Raton, 1997.

5. Likens, G. E.; Chem. Eng. News 1976, 22, 29.
6. Piccolo, M. C.; Perillo, G. M. E.; Varela, P.; Environ. Sci. Technol. 1988, 22, 216.

7. Mohnen, V. A.; Sci. Am. 1988, 259, 14.

8. Sakugawa, H.; Kaplan, I. R.; Shepard, L. S.; Atmos. Environ. 1993, 27, 203.

9. Kumar, N.; Kulshrestha, U. C.; Saxena, A.; Khare, P.; Kumari, K. M.; Srivastava, S. S.; J. Atmos. Chem. 1996, 23, 81.

10. Fornaro, A.; Gutz, I. G. R.; Atmos. Environ. 2003, 37, 117; Rocha, F. R.; Silva, J. A. F.; Lago, C. L.; Fornaro, A.; Gutz, I. G. R.; Atmos. Environ. 2003, 37, 105 .

11. Casado, H.; Ezcurra, A.; Durana, N.; Albala, J. L.; Garcia, C.; Ureta, I.; Lacaux, J. P.; Van Dinh, P.; Atm. Res. 1989, 22, 297.

12. Galloway, J. N.; Water, Air, Soil Pollut. 1995, 85, 15.

13. Puxbaum, H.; Simeonov, V.; Kalina, M. F.; Atmos. Environ. 1998, 32, 193.

14. Minoura, H.; Iwasaka, Y.; J. Atmos. Chem. 1996, 24, 39.

15. Tanner, P. A.; Heng-Chi, L.; Mei-Yuan, H.; Zhi-Lai, S.; J. Atmos. Chem. 1997, 27, 71 .

16. Moreira-Nordemann, L. M.; Forti, M. C.; Di-Lascio, V. L.; Espírito-Santo, C. M.; Danelon, O. M. Em Acidification in Tropical Countries; Rodhe, H.; Herrera, R., eds.; John Willey \& Sons Ltda, 1988.

17. Forti, M. C.; Moreira-Nordemann, L. M.; Andrade, M. F.; Orsini, C. Q.; Atmos. Environ. 1990, 24B, 355; Paiva, R. P.; Pires, M. A. F.; Andrade, M. F.; Gonçalves, F. F. L. T.; Massambani, O. ; Fresenius Environ. Bull. 1997, 6, 508.

18. Hontoria, C.; Saa, A.; Almorox, J.; Cuadra, L.; Sanchez, A.; Gasco, J. M.; Water, Air, Soil Pollut. 2003, 146, 35.

19. Fornaro, A.; Isolani, P. C.; Gutz, I. G. R.; Atmos. Environ. 1993, $27,307$.

20. Abbas, M. Z. M.; Bruns, R. E.; Scarminio, I. S.; Ferreira, J. R.; Environ. Pollut. 1993, 79, 225.

21. Vautz, W.; Schilling, M.; Gonçalves, F. L. T.; Solci, M. C.; Massambani, O.; Klockow, D.; Water, Air, Soil Pollut. 1995, 85, 1973.

22. Lara, L. B. L. S.; Artaxo, P.; Martinelli, L. A.; Victoria, R. L.; Camargo, P. B.; Krusche, A.; Ayers, G. P.; Ferraz, E. S. B.; Ballester, M. V.; Atmos. Environ. 2001, 35, 4937.

23. Carvalho, C. N.; Leprun, J. C.; Biogeochemistry 1991, 14, 99.

24. Figueredo, D. V.; Ambio 1999, 28, 514.

25. Luca, S. J.; Milano, L. B.; Ide, C. N.; Water Sci. Technol. 1991, 23, 133.

26. Alonso, C. D.; Romano, J.; Massaro, S.; Livro de Resumos da $37^{a}$ Reunião Anual da Sociedade Brasileira de Química, Belo Horizonte, Brasil, 1987.

27. Fornaro, A.; Dissertação de Mestrado, Universidade de São Paulo, Brasil, 1991.

28. Flues, M.; Hama, P.; Fornaro, A.; Quim. Nova 2003, 26, 479; Campos, V. P.; Costa, A. C. A.; Tavares, T. M.; Quim. Nova 1998, 21, 418.

29. Mello, W. Z.; Environ. Pollut. 2001, 114, 235.

30. Durst, R. A.; Davison, W.; Koch, W. F.; Pure \& Appl. Chem. 1994, 66, 649.

31. Miller, J. C.; Miller, J. N.; Statistics for Analytical Chemistry, $2^{\text {nd }}$ ed., John Wiley \& Sons: New York, 1988, cap. 5; Currie, L. A.; Anal. Chim. Acta 1999, 391, 105.

32. UNECE - United Nations Economic Commission for Europe, Manual Methods and criteria for harmonized sampling, assessment, monitoring and analysis of the effects of air pollution on forests, Part VI: Measurement of Deposition and Air Pollution, 1999.

33. Bouwman, A. F.; Lee, D. S.; Asman, W. A. H.; Detener, F. J.; Vander-Hoek, K. W.; Olivier, J. G. J.; Global Biogeochem. Cycles 1997, 11, 561; Rangel, M.C.; Carvalho, M. F. A.; Quim. Nova 2003, 26, 265; Félix, E. P.; Arnaldo, A. A.; Quim. Nova 2004, 27, 123.

34. Mergler, Y. J.; van Aalst, A.; Nieuwenhuys, B. E. Em Reduction of Nitrogen Oxide Emissions; Ozkan, U. S.; Agarwal, S. K.; Marcelin, G., eds.; ACS: Washington, 1995, cap. 15

35. Pirug, G.; Bonzel, H. P.; J. Catal. 1977, 50, 64.

36. Ryaboshapko, A. G.; Water, Air, Soil Pollut. 2001, 130, 205.

37. Kawamura, K.; Steinberg, S.; Kaplan, I. R.; Atmos. Environ. 1996, 30, 1035.

38. Souza, S. R.; Vasconcellos, P. C.; Carvalho, L. R. F.; Atmos. Environ. 1999, 33, 2563; Souza, S. R.; Carvalho, L. R. F.; Quim. Nova 1997, 20, 245. 